\title{
Distribution of dengue vectors, Aedes aegypti and Aedes albopictus, in a few selected semi-urban areas of the Central Province of Sri Lanka
}

\author{
F Noordeen ${ }^{1}$, MRM Raza ${ }^{1}$, FNN Pitchai ${ }^{1}$, WKC Saranga ${ }^{1}$, LKHB Sandeepani ${ }^{1}$, LD \\ Sadamali $^{1}$, MBTT Sanathchandra ${ }^{1}$, KRMHN Samarakoon ${ }^{1}$, MJF Rukshana ${ }^{1}$, RMM \\ Ratnayake $^{1}$, RCSB Ratnayake ${ }^{1}$, RMPM Ratnayake $^{1}$, HMSM Seanadheera $^{1}$
}

Sri Lankan Journal of Infectious Diseases 2018 Vol.8 (1):36-39

DOI: http://dx.doi.org/10.4038/sljid.v8i1.8141

\begin{abstract}
Aedes aegypti and Aedes albopictus are the two major vectors transmitting dengue viruses. The current study was undertaken from October to November 2014 to identify the distribution of dengue vectors in the Akurana Medical Officer of Health (MOH) division, which consisted of Akurana, Dunuwila and Alawathugoda Public Health Inspector (PHI) divisions. Larvae were collected from potential breeding sites in randomly selected houses in the selected PHI areas. Aedes larvae were incubated to emerge and the adults were differentiated into species using morphological features. Adult Aedes mosquitoes were pooled and tested for NS1 antigen. The total larvae collected were 700 and the total number of emerged adults were 171, consisting of 116 A. albopictus and 55 A. aegypti mosquitoes. None of the Aedes pools tested were positive for dengue NS1. A. albopictus was found to be abundant in the Akurana MOH division during the study period.
\end{abstract}

Keywords: Dengue vectors, Akurana MOH division, Aedes abundance, Dengue virus NSI.

\section{Introduction}

Dengue has been a persistent mosquito borne infectious disease endemic to Sri Lanka since the mid 1960's. ${ }^{1,2}$ Aedes aegypti and Aedes albopictus, only two of the 48 species of mosquitoes found in Sri Lanka, are known to transmit the dengue virus (DENV) from infected to susceptible individuals. ${ }^{1,2,3}$ Both these species of mosquitoes are prevalent throughout the island and are found in both urban and rural areas. ${ }^{2,3}$ Aedes mosquitoes are capable of transmitting the DENV but $A$. aegypti is thought to be the major vector responsible for almost all dengue epidemics. A. albopictus appears to be efficient in virus transmission and carriage but do not contribute to epidemics like A. aegypti. ${ }^{1,3,4}$

Dengue outbreaks in Sri Lanka are seasonal and correlate with an increase in the vector density. These outbreaks generally occur twice a year, particularly after the monsoon rains, once in June/July and the other from October to December. ${ }^{1,3,4}$ A. aegypti and A. albopictus are known to thrive in clean or organically rich waters, either in a natural or artificial system

${ }^{1}$ Department of Microbiology, Faculty of Medicine, University of Peradeniya, Sri Lanka

Address for correspondence: Prof Faseeha Noordeen, Department of Microbiology, Faculty of Medicine, University of Peradeniya, Sri Lanka. Telephone: +94812396530 Email: faseeha.noordeen12@gmail.com;

faseehan@pdn.ac.lk (iD https://orcid.org/0000-0002-2018-0606

Received 23 May 2017 and revised version accepted 10 March 2018 
such as containers. ${ }^{3}$ They are also found to thrive in brackish water systems across the coasts of the island. ${ }^{5}$ A. albopictus is an outdoor breeder while A. aegypti is an indoor breeder. Higher temperatures correlate with an increase in vector density and feeding. ${ }^{2}$ Cities and towns situated in low altitudes have been found to be infested with higher populations of the vector than cities and towns situated at high altitudes. ${ }^{6,7}$

Changing climate and extended heavy rainfalls often lead to floods causing a high level of vector breeding. In addition, an accelerated rate of urbanisation and deforestation in dengue endemic tropical developing countries contribute to vector abundance and thus increases the chances of DENV transmission. Identifying and mapping of dengue vectors and their dynamics are important if effective dengue control is to be achieved. ${ }^{4,7}$ Despite a number of studies on DENV vectors in some parts of Sri Lanka, not all areas in the country are regularly surveyed for vector distribution. One such area is the Akurana $\mathrm{MOH}$ division, located in the Central Province of the country, which experiences regular dengue outbreaks.

The objective of this study was to identify DENV vector distribution in the Akurana MOH division during an early part of the dengue season. ${ }^{8}$

\section{Materials and Methods}

The study was carried out in the PHI divisions of Akurana, Dunuwila and Alawathugoda from October to November 2014 during the early part of the dengue season in the Central Province. ${ }^{8}$ Outdoor larval collection was carried out from potential breeding sites (cement tanks, plastic barrels, concrete slabs, tyres, discarded yoghurt cups and cut bamboo tree ends) around randomly selected houses in suburban areas. The larvae from these habitats were collected using dippers and pipettes. The larvae were then allowed to emerge into adults under appropriate conditions in the laboratory and the emerged mosquitoes were collected through an oral aspirator. Adult Aedes mosquitoes were differentiated using morphological features. ${ }^{9}$ Pools of adult Aedes mosquitoes of each species from each site were homogenised with PBS under sterile conditions. The homogenate was then tested for dengue NS1 antigen using a rapid immunochromatography (ICT) assay (SD Diagnostics, Korea). The manufacturer's instructions were followed carefully to carry out the DENV NS1 antigen testing in the Aedes mosquito pools.

\section{Results}

The total number of Aedes larvae collected from the study areas were 769 (Table 1) and the total number of adult Aedes mosquitoes emerged from the larvae were 171. These included $116(67.8 \%)$ A. albopictus adults and 55 (32.2\%) A. aegypti adults (Table 2). A. albopictus

Table 1: Aedes larvae collected from Akurana $\mathrm{MOH}$ area including 3 PHI divisions.

\begin{tabular}{cc}
\hline PHI Division & Number of larvae \\
\hline Alawathugoda & 207 \\
Akurana & 354 \\
Dunuwila & 208 \\
\hline Total & $\mathbf{7 6 9}$ \\
\hline
\end{tabular}
was found in abundance in the Akurana $\mathrm{MOH}$ division. None of the 12 Aedes pools from the study sites were positive for DENV NS1 antigen when tested using the rapid ICT assay indicating the absence of DENV in the tested pools (Table 2). 
Table 2. Total number of Aedes mosquitoes emerged from larvae and Aedes pools tested for NS1 antigen

\begin{tabular}{|c|c|c|c|c|c|}
\hline \multicolumn{2}{|c|}{ PHI area } & \multicolumn{2}{|c|}{ Aedes aegypti } & \multicolumn{2}{|c|}{ Aedes albopictus } \\
\hline & & $\begin{array}{l}\text { No of adult } \\
\text { mosquitoes }\end{array}$ & $\begin{array}{c}\text { Serial No of } \\
\text { the pool } \\
\text { tested }\end{array}$ & $\begin{array}{l}\text { No of adult } \\
\text { mosquitoes }\end{array}$ & $\begin{array}{c}\text { Serial No of } \\
\text { the pool } \\
\text { tested }\end{array}$ \\
\hline \multirow[t]{2}{*}{ Alawathugoda } & Male & 15 & 1 & 20 & 2 \\
\hline & Female & 13 & 3 & 15 & 4 \\
\hline \multirow[t]{2}{*}{ Akurana } & Male & 9 & 5 & 34 & 6 \\
\hline & Female & 3 & 7 & 31 & 8 \\
\hline \multirow[t]{2}{*}{ Dunuwila } & Male & 6 & 9 & 11 & 10 \\
\hline & Female & 9 & 11 & 5 & 12 \\
\hline \multicolumn{2}{|c|}{ Total } & 55 & & 116 & \\
\hline
\end{tabular}

\section{Discussion}

Global epidemiological studies on DENV vector prevalence indicate A. aegypti to be the abundant vector in dengue endemic areas. However, in the current study A. albopictus was found to be the more abundant vector. Findings of the current study are supported by a few other studies done in Sri Lanka in similar urban and suburban regions. ${ }^{10,11}$ A study on the prevalence and breeding habitats of A. aegypti and A. albopictus in the semi-urban areas of Kandy and Kurunegala with contrasting climatic patterns over a 12 month period from June 2007 to May 2008 reported the predominance of A. albopictus in the study areas. ${ }^{9}$ Another study carried out by Ekiriyagala $e t a l^{10}$ from July to September 2011 from selected urban and suburban areas of Kegalle and Peradeniya also found A. albopictus to be the more abundant vector. Similar observations have also been made on the prevalence of DENV vectors in a study carried out in the urban and suburban regions of Assam, India. ${ }^{12}$ This study indicated that A. albopictus was the predominant mosquito species in the suburbs while A. aegypti was the predominant vector in the cities in Assam, India.

Dengue NS1 antigen can be used to detect the presence of dengue virus in mosquitoes. ${ }^{13}$ However, in the present study, the NS1 antigen test was negative in all emerged A. albopictus and $A$. aegypti pools. This might be because adult mosquitoes which emerged directly from the larvae were tested rather than those directly from the field. Adults that emerge in captivity may have had no chance to feed on an infected patient. The presence of DENV NS1 in the homogenised pools, if positive, would have been an indicator of possible vertical transmission of the virus from the breeding adult to the captured larvae in the given sites. The negative NS1 results may therefore be also due to the absence of vertical transmission in the larvae from the parent mosquito. A third possibility for these negative results is that the viral load present in the newly emerged mosquitoes might have been inadequate for detection by the DENV NS1 test used. The use of more sensitive test methods such as RT-PCR for testing the presence of DENV nucleic acid in these mosquitoes would be useful.

\section{Conflict of Interest}

There are no conflicts of interest. 


\section{Ethics}

This work required collection of Aedes larvae with the public health authorities as part of their routine dengue control activities. The publication does not require ethical approval.

\section{References}

1. Vitarana T, Jayakuru WS, Withane N. Historical account of dengue haemorrhagic fever in Sri Lanka. WHO/SEARO Dengue Bulletin 1997; 21:117-118. URL: http://apps.who.int/iris/bitstream/10665/148517/1/dbv21p117.pdf

2. Sirisena PDNN, Noordeen F. Evolution of dengue in Sri Lanka - changes in the virus, vector, and climate. International Journal of Infectious Diseases 2014; 829:1-7. doi: 10.1016/j.ijid.2013.10.012

3. Kusumawathie PH, Fernando WP. Breeding habitats of Aedes aegypti Linnaeus and Ae. albopictus Skuse in a dengue transmission area in Kandy, Sri Lanka. The Ceylon Journal of Medical Science 2003; 46:51-60. No doi

4. PDNN Sirisena, F Noordeen. Dengue control in Sri Lanka - Challenges and prospects for improving current strategies. Sri Lankan Journal of Infectious Diseases 2016; 6 (1):2-16. doi: http://dx.doi.org/10.4038/sljid.v6i1.8107

5. Ramasamy R, Surendran SN, Jude JP, et al. Larval development of Aedes aegypti and Aedes albopictus in peri-urban brackish water and its implications for transmission of arboviral diseases. PLoS Neglected Tropical Diseases 2011; 5:e1369-e1379. doi: http://dx.doi.org/10.1371/journal.pntd.0001369

6. Kalra NL, Kaul SM, Rastogi RM. Prevalence of Aedes aegypti and Aedes albopictus vectors of DF/DHF in North, North East and Central India. Dengue Bulletin 1997; 21:84-92. No doi URL: http://apps.who.int/iris/bitstream/10665/148533/1/dbv21p84.pdf

7. Sirisena P, Noordeen F, Kurukulasuriya $H$, et al. Effect of climatic factors and population density on the distribution of dengue in Sri Lanka: A GIS Based Evaluation for Prediction of Outbreaks. PLoS ONE 2017; 12(1): e 0166806. doi: http://dx.doi.org/10.1371/journal.pone.0166806

8. Epidemiology Unit, Ministry of Health, Sri Lanka. http://www.epid.gov.lk/web/index.php?option=com_casesanddeaths\&Itemid=448\&lang=en\#

9. Genus Aedes - Florida Medical Entomology Laboratory. fmel.ifas.ufl.edu/key/genus/aedes.shtml

10. Weeraratne TC, Perera MDB, Mansoor M, et al. Prevalence and breeding habitats of the dengue vectors Aedes aegypti and Aedes albopictus (Diptera: Culicidae) in the semi-urban areas of two different climatic zones in Sri Lanka. International Journal of Tropical Insect Science 2013; 33(4) 216-226 doi: 10.1017/S174275841300026X

11. Ekiriyagala WRSK, Noordeen F, Pitchai FNN, et al. Abundance and dengue virus dynamics of Aedes aegypti and Aedes albopictus in selected urban areas of Kegalle and Peradeniya. Sri Lankan Journal of Infectious Diseases 2015; 5(1):19-21 doi: http://doi.org/10.4038/sljid.v5i1.7808

12. Dev V, Khound K, Tewari GG. Dengue vectors in urban and suburban Assam, India: entomological observations. WHO South East Asia Journal of Public Health 2014; 3(1):51-59. No doi URL: http://www.searo.who.int/publications/journals/seajph/seajphv3n1p51.pdf

13. Tan CH, Wong PSJ, Li MZI, Vythilingam I, Ng LC. Evaluation of the Dengue NS1 Ag Strip® for detection of dengue virus antigen in Aedes aegypti (Diptera: Culicidae). Vector-Borne and Zoonotic Diseases 2011; 11:789-792. doi: http://doi.org/10.1089/vbz.2010.0028 